\title{
Adaptive divergence in resistance to herbivores in Datura stramonium
}

Guillermo Castillo, Pedro L Valverde, Laura L Cruz, Johnattan Hernández-Cumplido, Guadalupe Andraca-Gómez, Juan Fornoni, Edson Sandoval-Castellanos, Erika Olmedo-Vicente, César M Flores-Ortiz, Juan Núñez-Farfán

Defensive traits exhibited by plants vary widely across populations. Heritable phenotypic differentiation is likely to be produced by genetic drift and spatially restricted gene flow between populations. However, spatially variable selection exerted by herbivores may also give rise to differences among populations. To explore to what extent these factors promote the among-population differentiation of plant resistance of 13 populations of Datura stramonium, we compared the degree of phenotypic differentiation (PST) of leaf resistance traits (trichome density, atropine and scopolamine concentration) against neutral genetic differentiation (FST) at microsatellite loci. Results showed that phenotypic differentiation in defensive traits among-population is not consistent with divergence promoted by genetic drift and restricted gene flow alone. Phenotypic differentiation in scopolamine concentration was significantly higher than FST across the range of trait heritability values. In contrast, genetic differentiation in trichome density was different from FST only when heritability was very low. On the other hand, differentiation in atropine concentration differed from the neutral expectation when heritability was less than or equal to 0.3 . In addition, we did not find a significant correlation between pair-wise neutral genetic distances and distances of phenotypic resistance traits. Our findings reinforce previous evidence that divergent natural selection exerted by herbivores has promoted the among-population phenotypic differentiation of defensive traits in $D$. stramonium. 
1 Guillermo Castillo ${ }^{1}$

2 Pedro L. Valverde ${ }^{2}$

3 Laura L. Cruz ${ }^{1}$

4 Hernández-Cumplido Johnattan ${ }^{3}$

5 Guadalupe Andraca-Gómez ${ }^{1}$

6 Juan Fornoni ${ }^{1}$

7 Edson Sandoval-Castellanos ${ }^{1}$

8 Erika Olmedo-Vicente ${ }^{1}$

9 César Mateo Flores-Ortiz ${ }^{4}$

10 Juan Núñez-Farfán ${ }^{1 *}$

$11 *$ Corresponding author

12 farfan@unam.mx

13 Phone number: 56229009

14 Affiliations

$15{ }^{1}$ Laboratorio de Genética Ecológica y Evolución, Departamento de Ecología Evolutiva, Instituto

16 de Ecología, Universidad Nacional Autónoma de México. Circuito Exterior, Ciudad

17 Universitaria, 14510, Distrito Federal, México.

18 2Departamento de Biología, Universidad Autónoma Metropolitana-Iztapalapa, Apartado Postal

19 55-535, 09340, Distrito Federal, México.

20 3nstitute of Biology, University of Neuchâtel (UNINE), Emile Argand 11, 2009 Neuchâtel,

21 Switzerland.

$22{ }^{4}$ Facultad de Estudios Superiores Iztacala, Universidad Nacional Autónoma de México, Apartado

23 Postal 314, 54090, Estado de México, México. 


\section{Introduction}

26 Most species consist of a series of populations that are often phenotypically differentiated (Rice

27 \& Jain, 1985; Thompson, 2005). Heritable phenotypic differentiation in multiple traits can be

28 effectively produced by processes like genetic drift, mutation, founder effects or population

29 isolation (Gomulkiewicz et al., 2007). However, phenotypic differentiation in traits that

30 contribute to individuals' fitness may also have a spatial structure caused by varying selective

31 regimes exerted by biotic and/or abiotic factors (Holsinger \& Weir, 2009). Furthermore,

32 stabilizing selection may promote phenotypic similarity among populations (Merilä \& Crnokrak,

33 2001). Elucidating to what extent these processes promote character differentiation among

34 populations is central if we are to fully understand the prevalence of among-population variation

35 in the wild (Lynch, 1990; Althoff \& Thompson, 1999; Criscione, Blouin \& Sunnucks, 2006;

36 Kelly, 2006; Gomulkiewicz et al., 2007). Here we aimed to determine if among-population

37 variation in traits that confer resistance to herbivores in the annual plant Datura stramonium is

38 consistent with a scenario of varying selection or genetic drift and restricted gene flow.

To infer whether natural selection explains the observed differentiation among populations in putatively adaptive quantitative characters $\left(Q_{S T}\right)$, it is necessary to contrast this

41 hypothesis against a null model of differentiation at adaptively neutral loci $\left(F_{S T}\right.$; Spitze, 1993 ,

42 Guillaume, Chapuis \& Goudet, 2008; Whitlock, 2008). The detection of a significant difference

43 between the estimators of differentiation, $Q_{S T}$ and $F_{S T}$, may imply adaptive differentiation among

44 populations. The comparison of the differentiation indices has three possible outcomes each with

45 a unique interpretation (see Table 1 in Merilä \& Crnokrak, 2001). When $Q_{S T}$ and $F_{S T}$ are

46 statistically equal, this implies that the degree of differentiation in quantitative traits could be 
47 produced by drift alone. This does not necessarily imply that genetic drift produced the observed

48 phenotypic differentiation but that the roles of selection and drift are indiscernible. When $Q_{S T}<$

$49 F_{S T}$, it means that natural selection might be favoring the same phenotype across populations.

50 Finally, when $Q_{S T}$ significantly exceeds $F_{S T}$, it means that directional selection is favoring

51 different phenotypes in different populations. When $Q_{S T}$ and $F_{S T}$ are equal, it is expected that

52 both indices, estimated among pairs of populations of the same species, will be positively

53 correlated, implying isolation by distance, restricted gene flow and genetic drift (although a

54 partial role of selection could be involved also), or high recombination between molecular

55 neutral marker loci and quantitative trait loci (Merilä \& Crnokrak, 2001). In contrast, no

56 correlation between both indices of differentiation among local populations may implicate a role

57 of natural selection (see Discussion).

In order to explore the signals of non-neutral evolution in quantitative traits it is

necessary to estimate $Q_{S T}$ and $F_{S T} . F_{S T}$ is commonly estimated by analyzing variance in allele

60 frequency (Wright, 1951) at molecular markers, like microsatellite loci. On the other hand, to

61 estimate $Q_{S T}$ it is necessary to know the amount of additive genetic variance of quantitative traits

62 in many local populations (Spitze, 1993). However, accomplishing the latter objective it is not

63 feasible for a large number of populations because it requires estimating the breeding values of

64 genotypes (families) for a suite of phenotypic characters in each local population. $P_{\mathrm{ST}}$ (degree of

65 phenotypic differentiation index) is an analogous index to $Q_{\mathrm{ST}}$ (Leinonen et al., 2006, 2013),

66 useful for exploring if phenotypic differentiation among populations exceeds genetic

67 differentiation in neutral markers (Merilä \& Crnokrak, 2001). The use of $P_{\mathrm{ST}}$ instead of $Q_{\mathrm{ST}}$ is

68 justified when estimates of additive genetic variance are not available (Leinonen et al., 2006,

69 2013; Lehtonen et al., 2009). Estimation of additive genetic variation in traits makes it necessary 
70 to obtain the phenotypic covariance between relatives (families) with an experimental common

71 garden and/or the use of reciprocal transplant experiments to rule out the environmental effects

72 on phenotypes. Hence, $P_{S T}$ can be used as a surrogate of $Q_{S T}$.

73

74

75

76

77

78

79

80

81

82

83

84

85

86

87

88

89

90

91

92

Resistance traits exhibited by plants (i.e., traits that prevent/reduce damage by natural enemies) vary widely across populations (Núñez-Farfán, Fornoni \& Valverde, 2007; Züst et al., 2012). Selection exerted by herbivores is a major force driving the evolution of plants' resistance traits (Rausher, 2001; Anderson \& Mitchell-Olds, 2011; Züst et al., 2012). Thus, amongpopulation differentiation in resistance traits is likely to be produced by spatial variation in the local selective regimes exerted by herbivores. Such spatially variable selection can be generated by among-population variation in the abundance, species composition, feeding styles, and degree of dietary specialization of herbivores to their host plants (Falconer \& Mackay 1996;

Charlesworth, Nordborg \& Charlesworth, 1997; Parchman \& Benkman 2002; Arany et al., 2008; Hare, 2012). Datura stramonium (Solanaceae) provides an optimal system for studying amongpopulation differentiation in resistance traits. Because of its wide distribution (Mexico, Canada, United States, and Europe), D. stramonium is exposed to different environmental conditions and to a wide diversity of herbivore species (Weaver \& Warwick, 1984; Valverde, Fornoni \& NúñezFarfán, 2001; Cuevas-Arias, Vargas \& Rodríguez, 2008). Resistance against herbivores in $D$. stramonium includes leaf trichomes (Valverde, Fornoni \& Núñez-Farfán, 2001; KariñhoBetancourt \& Núñez-Farfán, 2015) and tropane alkaloids (Shonle \& Bergelson, 2000), of which atropine, hyosciamine and scopolamine are the most abundant (Parr et al., 1990; KariñhoBetancourt et al., 2015). These secondary metabolites affect the activity of the neurotransmitter acetylcholine (Roddick, 1991) with negative effects on insects and vertebrate herbivores (Hsiao \& Fraenkel, 1968; Krug \& Proksch, 1993; Wink, 1993; Shonle, 1999; Mithöfer \& Boland, 2012). 
93 Recent studies have found ample geographic variation in leaf trichome density and atropine and

94 scopolamine concentration in central Mexico (Castillo et al., 2013, 2014). However, it is unclear

95 if selection by herbivores or neutral processes, among other factors, can account for the observed

96 among-population differentiation in these resistance traits.

97 Here, we assessed to what extent population differentiation in resistance leaf traits

98 (trichome density, atropine and scopolamine concentrations) of $D$. stramonium is accounted by

99 neutral processes (genetic drift and restricted gene flow) or divergent natural selection. To do so,

100 we compared the degree of phenotypic differentiation of resistance traits by means of $P_{\mathrm{ST}}$

101 estimated for the whole range of values of heritability, with the neutral expectation set by allelic

102 divergence at microsatellite loci $\left(F_{\mathrm{ST}}\right)$. We expect that $P_{\mathrm{ST}}$ of each resistance character would be

103 significantly higher than the index of population differentiation in neutral molecular markers

$104\left(F_{\mathrm{ST}}\right)$, since previous studies have detected contrasting selection exerted by herbivores on the

105 three characters.

107 Methods

108 Study system

109 Datura stramonium L. (Solanaceae) is an annual herb commonly found in roadsides, cultivated

110 areas and disturbed environments in Mexico, the United States, Canada, and Europe (Valverde,

111 Fornoni \& Núñez-Farfán, 2001; Weaver, Dirks \& Warwick, 1985; van Kleunen, Markus \&

112 Steven, 2007). In Mexico, leaves of $D$. stramonium are consumed by a dietary specialist

113 herbivore, the chrysomelid Lema trilineata (Núñez-Farfán \& Dirzo, 1994), the dietary 
114 oligophagous Epitrix parvula (Chrysomelidae), which also feeds from other members of the

115 Solanaceae family (Glass, 1940), and by the dietary generalist grasshopper Sphenarium

116 purpurascens (Núñez-Farfán \& Dirzo, 1994). Datura stramonium features leaf trichomes and

117 tropane alkaloids (atropine and scopolamine) as resistance traits against herbivory. These traits

118 have shown heritable basis (Shonle \& Bergelson, 2000; Valverde, Fornoni \& Núñez-Farfán,

119 2001; Kariñho-Betancourt \& Núñez-Farfán, 2015), and are under selection by dietary specialist

120 and generalist herbivores (Castillo et al., 2014).

122 Fieldwork

123 During August-September 2007 we sampled 13 natural populations of D. stramonium in central

124 Mexico (Fig. 1). Selected populations inhabit a wide range of habitat types. The geographic

125 location and climatic characteristics are shown in Table 1. From each population we sampled 30

126 randomly chosen individual plants.

127

128

Resistance traits quantification

129 Following Valverde, Fornoni \& Núñez-Farfán (2001), we estimated leaf trichome density as the

130 total number of trichomes in an observation field of $2.5 \mathrm{~mm}^{2}$ located in the central basal region

131 of the adaxial side of the leaf, using a stereoscopic microscope. Then we averaged the trichome

132 density per plant from a random sample of 20 fully expanded leaves. We also quantified the

133 concentration of atropine and scopolamine (two major alkaloids in D. stramonium) from a

134 sample of 20 leaves per plant by means of High Precision Liquid Chromatography (HPLC). 
135 Details of the extraction method and HPLC conditions can be found elsewhere (see Castillo et

136 al., 2013).

138 Data analysis

139 We estimated the neutral genetic differentiation among populations of $D$. stramonium using $F_{\text {ST }}$

140 values obtained from five nuclear microsatellite markers designed specifically for D. stramonium

141 as reported by Andraca-Gómez (2009). $F_{\mathrm{ST}}$ values were calculated using FSTAT 2.9.3.1

142 (Goudet, 2001) employing approximately 30 individuals per population. In addition, we assessed

143 the statistical power of our five microsatellites by means of Wright-Fisher simulations as

144 implemented in the program PowSim (Ryman \& Palm, 2006). The program requires a

145 divergence time and effective populations sizes so we tested a number of feasible combinations.

147 Phenotypic divergence in resistance traits - We used the degree of among-population

148 phenotypic divergence $\left(P_{\mathrm{ST}}\right)$ to explore if restricted gene flow and genetic drift $\left(F_{\mathrm{ST}}\right)$ alone can

149 account for this differentiation or if there is a signal of differentiation promoted by divergent

150 selection on resistance traits (Leinonen et al., 2006; Pujol et al., 2008). We estimated $P_{\mathrm{ST}}$ as

151

$$
P_{S T}=\frac{\sigma_{G B}^{2}}{\sigma_{G B}^{2}+2\left(h^{2} \bullet \sigma_{G W}^{2}\right)},
$$


152 where $\sigma_{G B}^{2}$ is the variance among populations, $\sigma_{G W}^{2}$ is the variance within population, and $h^{2}$ is

153 the trait heritability (Leinonen et al. 2006). Since this is not feasible for a large number of 154 populations we used an approximation by $P_{\mathrm{ST}}$.

155 In order to obtain $P_{\mathrm{ST}}$ values for resistance traits, we simulated the whole range of

156 heritabilities $\left(0 \leq h^{2} \leq 1\right)$. To estimate $P_{\mathrm{ST}}$ values we fitted a linear model for each resistance

157 trait, under the assumption that the distribution of resistance traits was normally distributed. The

158 population term was considered as a random effect. To test the hypothesis that $P_{\mathrm{ST}}$ is higher than

$159 F_{\mathrm{ST}}$, a Monte Carlo test was carried out, approaching a sample of 10,000 deviates from both $P_{\mathrm{ST}}$

160 and $F_{\mathrm{ST}}$ by means of their estimated error. $P_{\mathrm{ST}}$ error was estimated from the likelihood errors of

161 its components (variances among- and within-populations), while $F_{\mathrm{ST}}$ error was obtained by

162 bootstrapping (Goudet, 2001). The 10,000 random deviates of $F_{\mathrm{ST}}$ and $P_{\mathrm{ST}}$ were compared and

163 the $p$-value was obtained as the proportion of comparisons in which the $F_{\mathrm{ST}}$ was equal or higher

164 than the $P_{\mathrm{ST}}$ (null hypothesis).

165 We further evaluated the pair-wise Pearson's correlation between $F_{\mathrm{ST}}$ and $P_{\mathrm{ST}}$ for all

166 populations. Neutral marker variation can be used as a neutral expectation against which the

167 phenotypic divergence of traits can be compared (Gomulkiewicz et al., 2007). If resistance

168 phenotypic differentiation between populations $\left(P_{\mathrm{ST}}\right)$ is the result of neutral processes rather than

169 selection, differentiation among populations in these traits should correlate positively with

170 differentiation in selectively neutral markers $\left(F_{\mathrm{ST}}\right)$ (Merilä \& Crnokrak, 2001; Gomulkiewicz et

171 al., 2007; Lethonen et al., 2009; Leinonen et al., 2013). We evaluated the pair-wise correlation

172 between the $F_{\mathrm{ST}}$ and $P_{\mathrm{ST}}$ for different scenarios of heritability $\left(h^{2}=0.1,0.25,0.5,0.75\right.$ and 1.0$)$. 
173 Statistical analyses were performed using JMP ${ }^{\circledR}$ version 9.0.0 (SAS Institute, Cary, NC, 1989-

174 2007).

175

\section{Results}

177 Among-population variation in resistance traits - A multivariate analysis of variance

178 (MANOVA) detected significant multivariate differences in the studied resistance traits of 13

179 populations of $D$. stramonium (Wilks' $\lambda=0.091, F_{36,331.64}=11.51, P<0.0001$ ). After the

180 subsequent univariate ANOVAs were applied, we found significant differences in trichome

181 density $\left(F_{12,126}=5.10, P<0.0001\right)$, atropine $\left(F_{12,126}=7.85, P<0.0001\right)$, and scopolamine

182 concentration $\left(F_{12,126}=23.33, P<0.0001\right)$. Mean leaf trichome density and mean atropine and

183 scopolamine concentration per population are shown in Figure 2.

185 Genetic differentiation between populations of D. stramonium - Genetic differentiation as

186 estimated by differences in allele frequency at microsatellite loci was moderate. $F_{S T}$ was 0.228

187 (S.E. $=0.039)$, which is well above the minimum detectable value $\left(F_{S T}=0.01\right)$ that our sample

188 and markers allowed with a statistical power of 0.94 .

Phenotypic divergence in resistance traits - Comparison of phenotypic $\left(P_{\mathrm{ST}}\right)$ and neutral genetic

191 marker divergence $\left(F_{\mathrm{ST}}\right)$ showed that $P_{\mathrm{ST}}$ values for scopolamine concentration were

192 significantly higher than the $F_{\mathrm{ST}}$ in all values of $h^{2}$ (Fig. 3). However, $P_{\mathrm{ST}}$ for atropine 
193 concentration was significantly higher than $F_{\mathrm{ST}}$ when $0 \geq h^{2} \leq 0.3$ (Figure 2), whereas $P_{\mathrm{ST}}$ of leaf

194 trichome density significantly exceeded $F_{\mathrm{ST}}$ only when $h^{2} \leq 0.1$ (Fig. 2).

195 Pair-wise correlation between $F_{\mathrm{ST}}$ and $P_{\mathrm{ST}}-$ We found no significant correlations between pair-

196 wise $F_{\mathrm{ST}}$ and $P_{\mathrm{ST}}$ values among populations for any of the three resistance characters (Table 2 ).

197 Most correlation values were small (i.e., $-0.135 \leq r \leq 0.034$ ).

\section{Discussion}

Results showed that phenotypic differentiation in resistance traits among population of $D$. stramonium is not consistent with divergence promoted by genetic drift and restricted gene flow alone (Pujol et al., 2008; Lehtonen et al., 2009). Phenotypic differentiation in scopolamine concentration was significantly higher than $F_{S T}$ across the range of $h^{2}$. In contrast, genetic differentiation in trichome density was different from $F_{S T}$ only when heritability was very low, and most phenotypic variation could be related to major environmental factors, like annual mean precipitation and temperature. Likewise, differentiation in atropine concentration seems to differ

207 from the neutral expectation only at low values of $h^{2}$. Furthermore, we did not find a correlation 208 between pair-wise neutral genetic distances and phenotypic distances of any of the three 209 resistance traits. Taken together, results suggest that natural selection could be involved in 210 phenotypic divergence on resistance traits among populations of $D$. stramonium. 
214 populations at microsatellite loci $\left(F_{S T}=0.228\right)$. Using this $F_{S T}$ value, the indirect estimate of

215 gene flow $(\mathrm{Nm})$ is 0.846 , suggesting restricted gene flow among populations of $D$. stramonium,

216 and not sufficient to prevent differentiation by genetic drift (Hedrick, 2000). This contrasts with

217 differentiation at neutral loci reported for other organisms where $F_{S T}$ is generally lower than

2180.228 (but see Merila \& Crnokrak, 2001). $P_{S T}$ index values statistically not different from this

219 value of $F_{S T}$ imply that quantitative phenotypic characters follow a pattern of drift-induced

220 divergence (Leinonen et al. 2006). Here we found that the $P_{S T}$ index of scopolamine was

221 significantly higher than $F_{S T}$ for all values of heritability considered (cf. Fig. 3). This result

222 strongly suggests that phenotypic differentiation among populations in scopolamine

223 concentration is congruent with a scenario of divergent selection exerted by herbivores among

224 populations. However, $P_{S T}$ of atropine and leaf trichome density was higher than $F_{S T}$ only when

225 heritability was $\leq 0.3$ and $\leq 0.1$, respectively. This implies that the proportion of genetic variance

226 among populations from total genetic variance is high for these characters (Lehtonen et al. 2009;

227 Leinonen et al. 2013). When genetic variance within populations is low, as implied by low

228 values of heritability, there a high opportunity to detect a significant $P_{S T}$ given that the among-

229 population genetic variance component has a relevant weight in the total phenotypic variance.

230 Inversely, when heritability is high, the within-population genetic component accounts for a high

231 fraction of total genetic variance rendering $P_{S T}$ very small. These considerations may explain

232 why $P_{S T}$ of trichome density and atropine are different from $F_{S T}$ only at very low heritability.

Although $P_{\mathrm{ST}}$ is used as an analog of $Q_{S T}$ (genetic differentiation in quantitative

234 characters) when it is not possible to obtain the amount of additive genetic variation (variance

235 among families, within populations)(Merila \& Cronkrak, 2006), conclusions derived from these

236 estimations must be interpreted with caution since this index can be biased by all environmental 
237 variation due to abiotic conditions among localities as well as environmental deviations within

238 populations, and non-additive genetic variation (v.gr., epistatic interactions, dominance, linkage

239 disequilibrium), among others (Pujol et al. 2008). Thus is relevant to ask whether $P_{S T}$ index

240 obtained for the resistance traits in D. stramonium posses genetic variance. Datura stramonium

241 displays a great variation among populations in trichome density and tropane alkaloids'

242 concentration in central Mexico (Castillo et al., 2013). Phenotypic variation in alkaloid

243 concentration, like other quantitative traits, is governed by environmental physical factors and

244 genetic variation (Castillo et al., 2013). Previous studies in this species have detected narrow-

245 sense $h^{2}$ of general resistance to herbivores of 0.49 and 0.41 in two natural populations of $D$.

246 stramonium (Fornoni, Valverde \& Núñez-Farfán, 2003; note that general resistance may include

247 physical and chemical defenses). In addition, broad-sense $h^{2}$ of general resistance and trichome

248 density has been estimated in 0.25 and 0.64 , respectively (Kariñho-Betancourt \& Núñez-Farfán,

249 2015). Also, genetic variance in trichome density among-populations (Valverde, Fornoni \&

250 Núñez-Farfán, 2001) and general resistance (Valverde, Fornoni \& Núñez-Farfán, 2003; Carmona

251 \& Fornoni, 2013) has been detected in D. stramonium. Finally, genetic variance in alkaloid

252 concentration (hyosciamine and scopolamine, and their ratio) has been detected previously by

253 Shonle \& Bergelson (2000). Thus, there is ample evidence of genetic basis of phenotypic

254 variation in resistance of $D$. stramonium to support our estimation of $P_{S T}$ values.

Because a $P_{S T}$ index higher than $F_{S T}$ means that divergent selection might be involved in population differentiation of resistance traits, at least for scopolamine, it is relevant to ask to what extent natural selection by herbivores is responsible for population differentiation in this character? In D. stramonium, several lines of evidence strongly suggest that differentiation in resistance is accounted by for herbivores. Differential and contrasting selection gradients on 
260 resistance to herbivores were detected between two populations of this species in a reciprocal 261 transplant experiment (Fornoni, Valverde \& Núñez-Farfán, 2004). Likewise, Shonle \&

262 Bergelson (2000) detected stabilizing selection on hyosciamine and directional selection to

263 reduce scopolamine concentration in $D$. stramonium. In a recent study of eight populations of $D$.

264 stramonium, Castillo et al. (2014) found that atropine is selected against by the dietary specialist

265 herbivores Epitrix parvula (in one population) and Lema daturaphila (in two populations). In

266 contrast, scopolamine was positively selected in one population where the specialist Lema

267 daturaphila was the main herbivore, whereas trichome density was positively selected in two

268 populations (one with L. daturaphila and one with the generalist grasshopper Sphenarium

269 puprurascens), and negatively selected in one population with the E. parvula (Castillo et al.,

270 2014). Thus, although genetic drift and restricted gene flow could produce phenotypic variation

271 in plant resistance among populations, the available evidence of spatially variable selection on

272 resistance traits in D. stramonium and data presented here suggests that population

273 differentiation can be potentially adaptive.

Furthermore, we did not detect any significant correlation between the pair-wise $P_{S T}$ and

$275 F_{S T}$ among population across the whole range of heritability, suggesting that differentiation at 276 quantitative traits and neutral molecular loci is decoupled. Theoretically, if the pace of

277 differentiation is dictated by genetic drift only, it is expected that differentiation indices will be 278 perfectly and positively correlated $\left(r=1, P_{S T}=F_{S T}\right.$; Fig. 4). If the correlation is positive but

279 lower than 1, then genetic drift has a role but does not explain all differentiation in quantitative 280 traits. In the region above the diagonal in Figure 4, where $P_{S T}>F_{S T}$, any positive pair-wise 281 correlation across populations, depicts a scenario where differentiation in quantitative traits 282 exceeds the neutral expectation and suggests divergent selection (Fig. 4). On the other hand, in 
283 the region below the diagonal, where $P_{S T}<F_{S T}$, any positive pair-wise correlation across

284 populations, portrays a scenario where differentiation at neutral molecular loci surpasses that of

285 quantitative characters suggesting a strong effect of genetic drift; however at moderate values of

$286 F_{S T}$ stabilizing selection might be favoring the same phenotype across populations (Fig. 4). When

$287 P_{S T}>F_{S T}$ and are uncorrelated (dotted line in Fig. 4) it shows another interesting scenario, as

288 found here. This implies that genetic drift and restricted gene flow alone cannot explain (Pujol et

289 al. 2008) the pattern of differentiation among populations in resistance traits in D. stramonium.

290 Under this scenario there is opportunity for divergence driven by selection in resistance traits.

291 Our results suggest that the higher $P_{S T}$ than $F_{S T}$ for scopolamine, together with spatial variation

292 in resistance traits and the existence of a selection mosaic detected previously by Castillo et al.

293 (2014) are consistent with outcomes predicted by the geographic mosaic of coevolution

294 (Thompson, 2005).

296 Acknowledgements

297 We thank very much to Professor M. Singer for his valuable revision to our manuscript. We

298 thank to Blanca Hernández, Martha Macías Rubalcava, María Teresa Caudillo, Luis Barbo and

299 Martha Urzúa Meza for helping us during HPLC quantification, and to Rosalinda Tapia-López

300 and the members of Laboratorio de Genética Ecológica y Evolución for their logistical support

301 and field assistance. Thanks are also extended to the Laboratorio de Alelopatía of Instituto de

302 Ecología, UNAM for providing the facilities for laboratory work. This paper constitutes a partial

303 fulfillment of the Graduate Program in Biological Sciences of the National Autonomous

304 University of Mexico (UNAM). 


\section{References}

307 Althoff DM, Thompson JN. 1999. Comparative geographic structures of two Parasitoid-Host interactions. Evolution 53:818-825.

309

310

311

312

313

314

315

316

317

318

319

320

321

322

323

324

325

326

Anderson JT, Mitchell-Olds T. 2011. Ecological genetics and genomics of plant defences: evidence and approaches. Functional Ecology 25:312-324.

Andraca-Gómez G. 2009. Genética de poblaciones comparada entre Datura stramonium y su herbívoro especialista Lema trilineata. Unpublished Master Thesis, Universidad Nacional Autónoma de México (UNAM), Mexico City.

Arany A, de Jong T, Kim H, van Dam N, Choi Y, Verpoorte R, van der Meijden E. 2008. Glucosinolates and other metabolites in the leaves of Arabidopsis thaliana from natural populations and their effects on a generalist and a specialist herbivore. Chemoecology $18: 65-71$.

Carmona D, Fornoni J. 2013. Herbivores can select for mixed defensive strategies in plants. New Phytologist 197: 576-585.

Castillo G, Cruz LL, Hernández-Cumplido J, Oyama K, Flores-Ortiz CM, Fornoni J, Valverde PL, Núñez-Farfán J. 2013. Geographic association and temporal variation of defensive traits and leaf damage in Datura stramonium. Ecological Research 28:663-672.

Castillo G, Cruz LL, Tapia-López R, Olmedo-Vicente E, Carmona D, Anaya-Lang AL, Fornoni J, Andraca-Gómez G, Valverde PL, Núñez-Farfán J. 2014. Selection mosaic exerted by specialist and generalist herbivores on chemical and physical defense of Datura stramonium. PloS one 9:e102478. 
327 Criscione CD, Blouin MS, Sunnucks P. 2006. Minimal selfing, few clones, and no amog-host

328

329

330 genetic structure in a hermaphroditic parasite with asexual propagation. Evolution 60:553-562.

Cuevas-Arias CT, Vargas O, Rodríguez A. 2008. Solanaceae diversity in the state of Jalisco, Mexico. Revista Mexicana de Biodiversidad 79:67-79.

Charlesworth B, Nordborg M, Charlesworth D. 1997. The effects of local selection, balanced polymorphism and background selection on equilibrium patterns of genetic diversity in subdivided populations. Genetical Research 70:155-174.

Falconer DS, Mackay T. 1996. Introduction to Quantitative Genetics. $4^{\text {th }}$ edition. Harlow UK: Addison-Wesley Longman.

Fornoni J, Valverde PL, Núñez-Farfán J. 2003. Quantitative genetics of plant tolerance and resistance against natural enemies of two natural populations of Datura stramonium. Evolutionary Ecology Research 5:1049-1065.

Fornoni J, Valverde PL, Núñez-Farfán J. 2004. Population variation in the cost and benefit of tolerance and resistance against herbivory in Datura stramonium. Evolution 58:16961704.

Glass EH. 1940. Host plants of the tobacco flea beetle. Journal of Economic Entomology 33:467470.

Gomulkiewicz R, Drown DM, Dybdahl MF, Godsoe W, Nuismer SL, Pepin KM, Ridenhour BJ, Smith CI, Yoder JB. 2007. Dos and don'ts of testing the geographic mosaic theory of coevolution. Heredity 98:249-258. 
348 Goudet J. 2001. FSTAT, a program to estimate and test gene diversities and fixation indices (version 2.9. 3). p 485-486.

350

351

352

353 354

355

356

357 358

359

360

361

362

363

364

Martin G, Chapuis E, Goudet J. 2008. Multivariate $Q_{S T} F_{S T}$ comparisons: a neutrality test for the evolution of the G matrix in structured populations. Genetics 180:2135-2149.

Hare JD. 2012. How Insect herbivores drive the evolution of plants. Science 338:50-51.

Hedrick PW. 2000. Genetics of Populations. $2^{\text {nd }}$ edition. Sudbury, MA: Jonesand Bartlett Publishers.

Hsiao TH, Fraenkel G. 1968. The role of secondary plant substances in the food specificity of the Colorado potato beetle. Annals of the Entomological Society of America 61:485-503.

Holsinger KE, Weir BS. 2009. Genetics in geographically structured populations: defining,

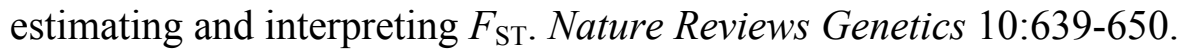

Kariñho-Betancourt E, Núñez-Farfán J. 2015. Evolution of resistance and tolerance to herbivores: testing the trade-off hypothesis. PeerJ e789.

Kariñho-Betancourt E, Agrawal AA, Halitschke R, Núñez-Farfán J. 2015. Phylogenetic correlations among chemical and physical plant defenses change with ontogeny. New Phytologist 206:796-806.

Kelly JK. 2006. Geographical variation in selection, from phenotypes to molecules. The American Naturalist 167:481-495.

Van Kleunen M, Markus F, Steven DJ. 2007. Reproductive assurance through self-fertilization does not vary with population size in the alien invasive plant Datura stramonium. Oikos 116:1400-1412. 
369 Krug E, Proksch P. 1993. Influence of dietary alkaloids on survival and growth of Spodoptera littoralis. Biochemical and Systematic Ecology 21:749-756.

371

372

373

374

375

376

377

378

379

380

381

382

383

384

385

386

387

388

389

Lehtonen PK, Laaksonen T, Artemyev AV, Belskii E, Both C, Bureš S, Bushuev AV, Krams I, Moreno J, Mägi M. 2009. Geographic patterns of genetic differentiation and plumage colour variation are different in the pied flycatcher (Ficedula hypoleuca). Molecular Ecology 18:4463-4476.

Leinonen T, Cano J, Mäkinen H, Merilä J. 2006. Contrasting patterns of body shape and neutral genetic divergence in marine and lake populations of threespine sticklebacks. Journal of Evolutionary Biology 19:1803-1812.

Leinonen T, McCairns RS, O'Hara RB, Merilä J. 2013. $Q_{S T}-F_{S T}$ comparisons: evolutionary and ecological insights from genomic heterogeneity. Nature Reviews Genetics 14:179-190.

Lynch M. 1990. The rate of morphological evolution in mammals from the standpoint of the neutral expectation. The American Naturalist 136:727-741.

Merilä J, Crnokrak P. 2001. Comparison of genetic differentiation at marker loci and quantitative traits. Journal of Evolutionary Biology 14:892-903.

Mithöfer A, Boland W. 2012. Plant defense against herbivores: chemical aspects. Annual Review of Plant Biology 63:431-50.

Nuñez-Farfan J, Dirzo R. 1994. Evolutionary ecology of Datura stramonium L. in central Mexico: Natural selection for resistance to herbivorous insects. Evolution 48:423-436.

Núñez-Farfán J, Fornoni J, Valverde PL. 2007. The evolution of resistance and tolerance to herbivores. Annual Review of Ecology, Evolution, and Systematics 38:541-566. 
390 Parchman TL, Benkman CW. 2002. Diversifying coevolution between crossbills and black spruce on Newfoundland. Evolution 56:1663-1672.

392

393

394

395

396

397

Parr A, Payne J, Eagles J, Chapman B, Robins R, Rhodes M. 1990. Variation in tropane alkaloid accumulation within the solanaceae and strategies for its exploitation. Phytochemistry 29:2545-2550.

Pujol B, Wilson AJ, Ross RIC, Pannell JR. 2008. Are $Q_{S T} F_{S T}$ comparisons for natural populations meaningful? Molecular Ecology 17:4782-4785.

Rausher MD. 2001. Co-evolution and plant resistance to natural enemies. Nature 411:857-864.

Rice K, Jain S. 1985. Plant population genetics and evolution in disturbed environments. In: Pickett STA, White PS, eds. The ecology of natural disturbance and patch dynamics. New York: Academic Press, 287-303.

Roddick J. 1991. The importance of the solanaceae in medicine and drug therapy. In: Hawkes JG, Lester RN, Nee M, and Estrada N. eds. Solanaceae. III. Taxonomy, Chemistry, Evolution. Royal Botanic Garden Press, Kew, U.K. 7-23

Ryman N, Palm S. 2006. POWSIM: a computer program for assessing statistical power when testing for genetic differentiation. Molecular Ecology Notes 6:600-602.

Shonle I. 1999. Evolutionary ecology of tropane alkaloids. Ph.D. diss., University of Chicago, Chicago, IL.

Shonle I, Bergelson J. 2000. Evolutionary ecology of the tropane alkaloids of Datura stramonium L. (Solanaceae). Evolution 54:778-788. 
410 Spitze K. 1993. Population structure in Daphnia obtusa: Quantitative genetic and allozymatic $411 \quad$ variation. Genetics 135:367-374.

412 Thompson J. 2005. The Geographic Mosaic of Coevolution. Chicago: The University of Chicago 413 Press.

414 Valverde PL, Fornoni J, Núñez-Farfán J. 2001. Defensive role of leaf trichomes in resistance to 415 herbivorous insects in Datura stramonium. Journal of Evolutionary Biology 14:424-432.

416 Valverde PL, Fornoni J, and Núñez-Farfán J. 2003. Evolutionary ecology of Datura stramonium: 417 equal plant fitness benefits of growth and resistance against herbivory. Journal of 418 Evolutionary Biology 16:127-137.

419 Weaver SE, Warwick SI. 1984. The biology of Canadian weeds: 64. Datura stramonium L. 420 Canadian Journal of Plant Science 64:979-991.

421 Weaver SE, Dirks V, Warwick S. 1985. Variation and climatic adaptation in northern 422 populations of Datura stramonium. Canadian Journal of Botany 63:1303-1308.

423 Whitlock MC. 2008. Evolutionary inference from $Q_{S T}$. Molecular Ecology 17:1885-1896.

424 425 427 428 429 430 431

Wink M. 1993. Allelochemical properties or the raison d'etre of alkaloids. In: Cordell GA, ed. The Alkaloids. Vol. 43. New York: Academic Press. 1-118.

Wright S. 1951. The genetical structure of populations. Annals of Eugenics 15:323-354.

Züst T, Heichinger C, Grossniklaus U, Harrington R, Kliebenstein DJ, Turnbull LA. 2012. Natural enemies drive geographic variation in plant defenses. Science 338:116-119. 


\section{Table $\mathbf{1}$ (on next page)}

Table 1

Vegetation type, latitude, longitude, altitude and population means of leaf trichome density, and atropine and scopolamine concentrations of 13 populations of Datura stramonium in Central Mexico. DS $=$ desert shrub, POF $=$ Pine-Oak Forest, TDF $=$ tropical deciduous forest. 


\begin{tabular}{|c|c|c|c|c|c|c|c|}
\hline & $\begin{array}{l}\text { Vegetation } \\
\text { Type }\end{array}$ & Latitude & Longitude & $\begin{array}{l}\text { Altitude (m } \\
\text { a.s.l.) }\end{array}$ & $\begin{array}{l}\text { Trichome density } \\
\qquad\left(2.5 \times \mathrm{mm}^{2}\right)\end{array}$ & $\begin{array}{c}\text { Atropine } \\
(\mathrm{mg} / \mathrm{g})\end{array}$ & $\begin{array}{c}\text { Scopolamine } \\
(\mathrm{mg} / \mathrm{g})\end{array}$ \\
\hline 1. - Acatzingo & DS & -97.78 & 19.32 & 2160 & 8.99 & 0.295 & 0.159 \\
\hline 2. - Atlixco & DS & -98.42 & 18.98 & 1840 & 9.04 & 0.691 & 0.577 \\
\hline 3. - Esperanza & DS & -97.37 & 18.85 & 2278 & 9.57 & 0.535 & 0.542 \\
\hline 4. - Patria Nueva & $\mathrm{DS}$ & -98.96 & 20.38 & 2040 & 12.62 & 0.317 & 0.367 \\
\hline 5. - Тaxco & TDF & -99.66 & 18.5 & 1582 & 9.02 & 0.957 & 0.266 \\
\hline 6. - Teotihuacán & DS & -98.86 & 19.68 & 2294 & 8.73 & 0.437 & 0.353 \\
\hline 7. - Ticumán & TDF & -99.2 & 18.86 & 1210 & 6.6 & 0.938 & 1.889 \\
\hline 8. - Tlaxiaca & $\mathrm{DS}$ & -98.86 & 20.08 & 2340 & 9.36 & 0.288 & 0.458 \\
\hline 9. - Tula & DS & -99.35 & 20.05 & 2020 & 6.06 & 3.129 & 2.804 \\
\hline 10. - Tzin Tzun Tzan & POF & -101.58 & 19.63 & 2050 & 4.29 & 0.994 & 2.995 \\
\hline 11. - Valsequillo & DS & -98.11 & 18.91 & 2209 & 6.09 & 1.767 & 0.044 \\
\hline 12. - Xalmimilulco & POF & -98.38 & 19.2 & 1200 & 4.66 & 2.688 & 2.513 \\
\hline 13. - Zirahuén & POF & -101.91 & 19.43 & 2174 & 4.91 & 0.618 & 1.968 \\
\hline
\end{tabular}

3 


\section{Table 2 (on next page)}

Table 2

Correlation $(r)$ between pair-wise $P_{\mathrm{ST}}$ of three resistance traits and pair-wise $F_{\mathrm{ST}}$ for all populations of Datura stramonium, under different scenarios of heritability $\left(h^{2}=0.1,0.25\right.$, $0.5,0.75$ and 1.0$)$. 


\begin{tabular}{lccccc}
\hline Resistance trait & \multicolumn{5}{c}{$r$} \\
\hline & $h^{2}=0.1$ & $h^{2}=0.25$ & $h^{2}=0.5$ & $h^{2}=0.75$ & $h^{2}=1.0$ \\
\hline Atropine & -0.0644 & -0.0671 & -0.0655 & -0.0642 & -0.0637 \\
Scopolamine & 0.0264 & 0.0344 & 0.0348 & 0.0316 & 0.0278 \\
Trichome density & -0.135 & -0.1218 & -0.1053 & -0.0939 & -0.0855 \\
\hline
\end{tabular}




\section{Figure 1 (on next page)}

Figure 1

Sampled populations of Datura stramonium in Central Mexico (see Table 1). 


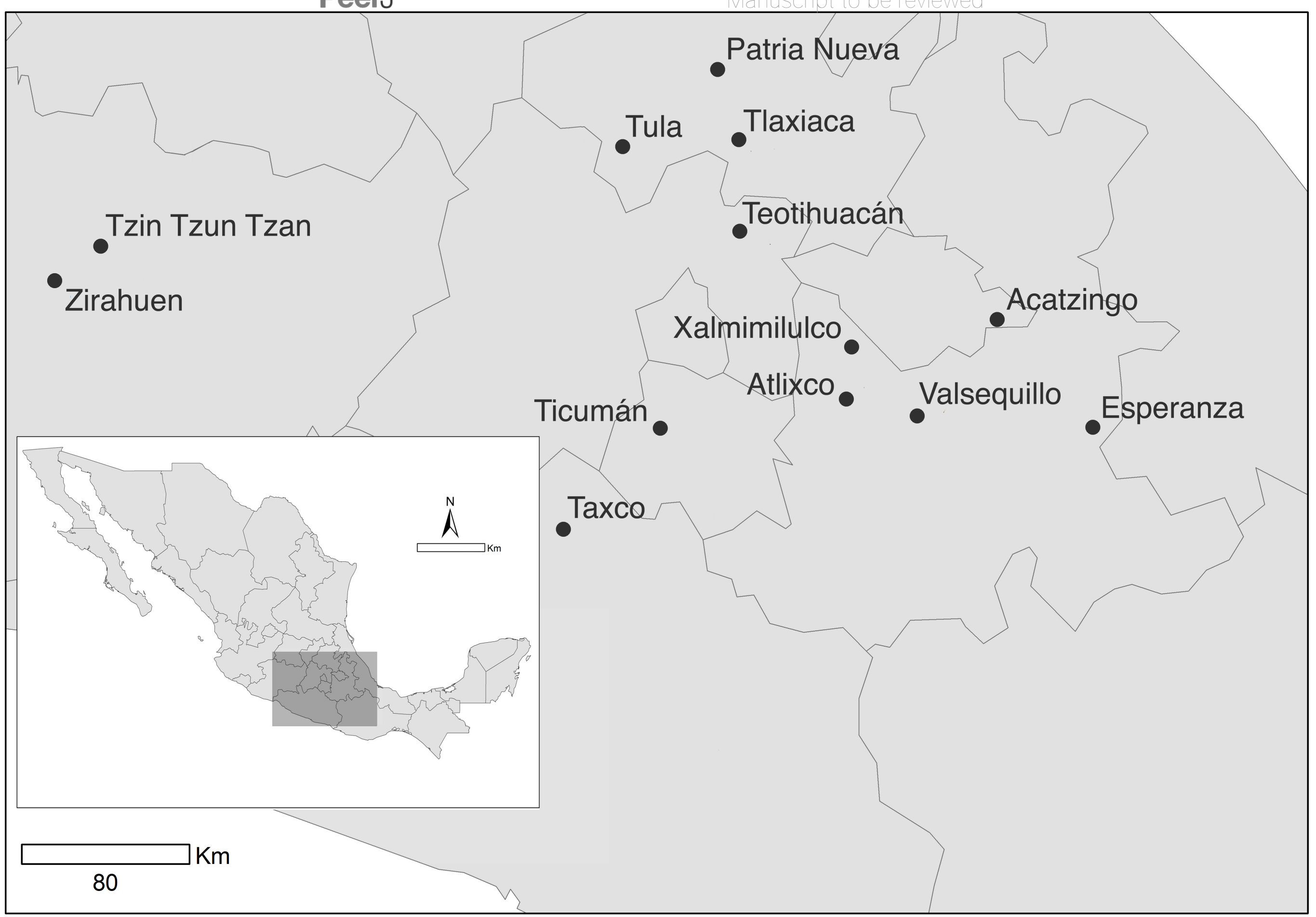




\section{Figure 2 (on next page)}

\section{Figure 2}

Among-population variation in leaf trichome density (a), and atropine and scopolamine concentration (b) in 13 populations of Datura stramonium in Central Mexico. Bars represent average value $+1 \mathrm{SE}$. 
a

Tั
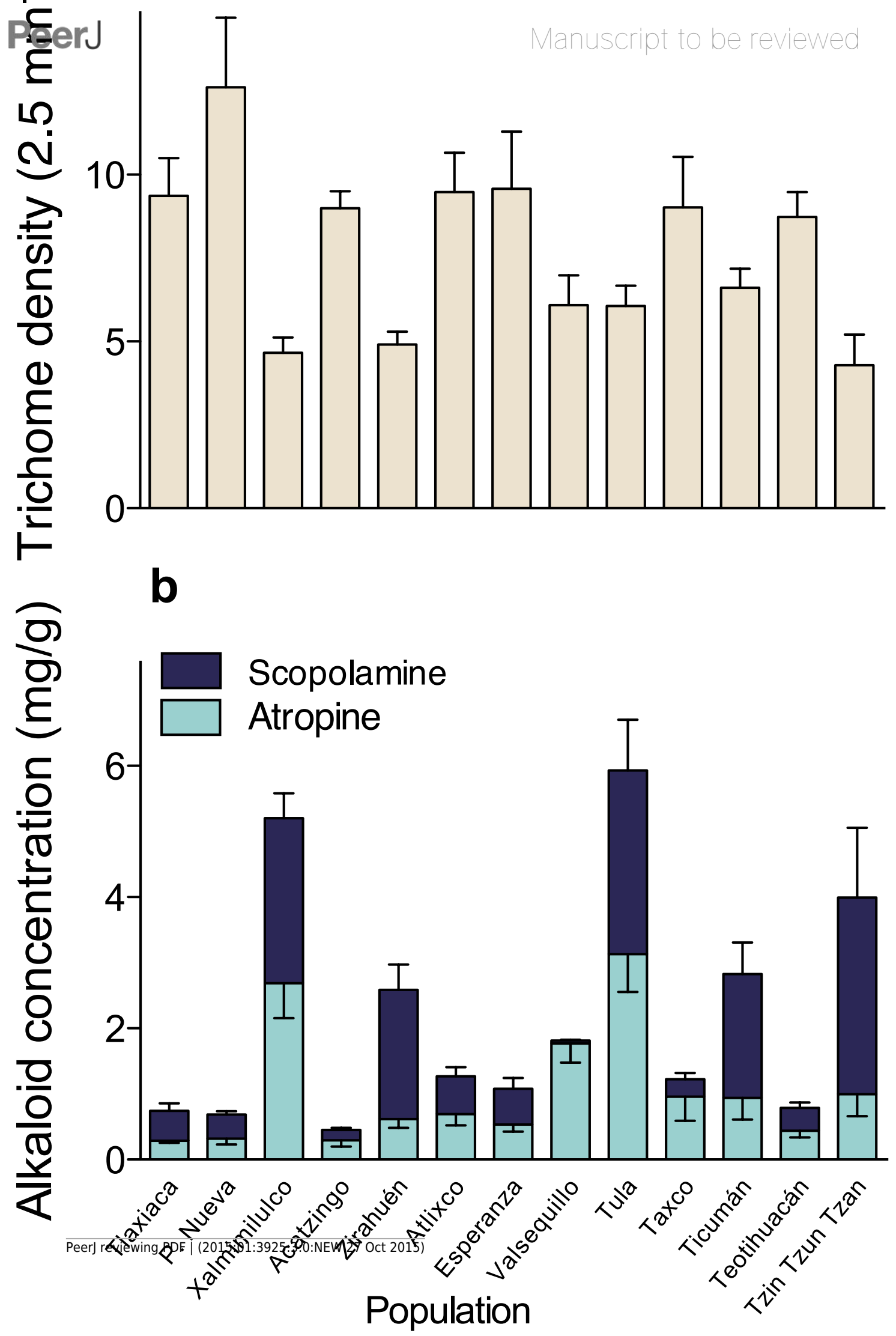
3

Figure 3

$P_{S T}$ values of putative defensive trait of Datura stramonium as a function of their genetic variance $\left(h^{2}\right)$ among populations. Confidence intervals of $50 \%$ and $95 \%$ are indicated by bars and lines, respectively. ${ }^{*}$ Represents overall $P_{S T}$ values that differ significantly from $F_{S T}$ (the black bar at the right end) after a Monte Carlo test $\left(10,000\right.$ deviates from both $P_{\mathrm{ST}}$ and $F_{\mathrm{ST}}$; see Methods). 


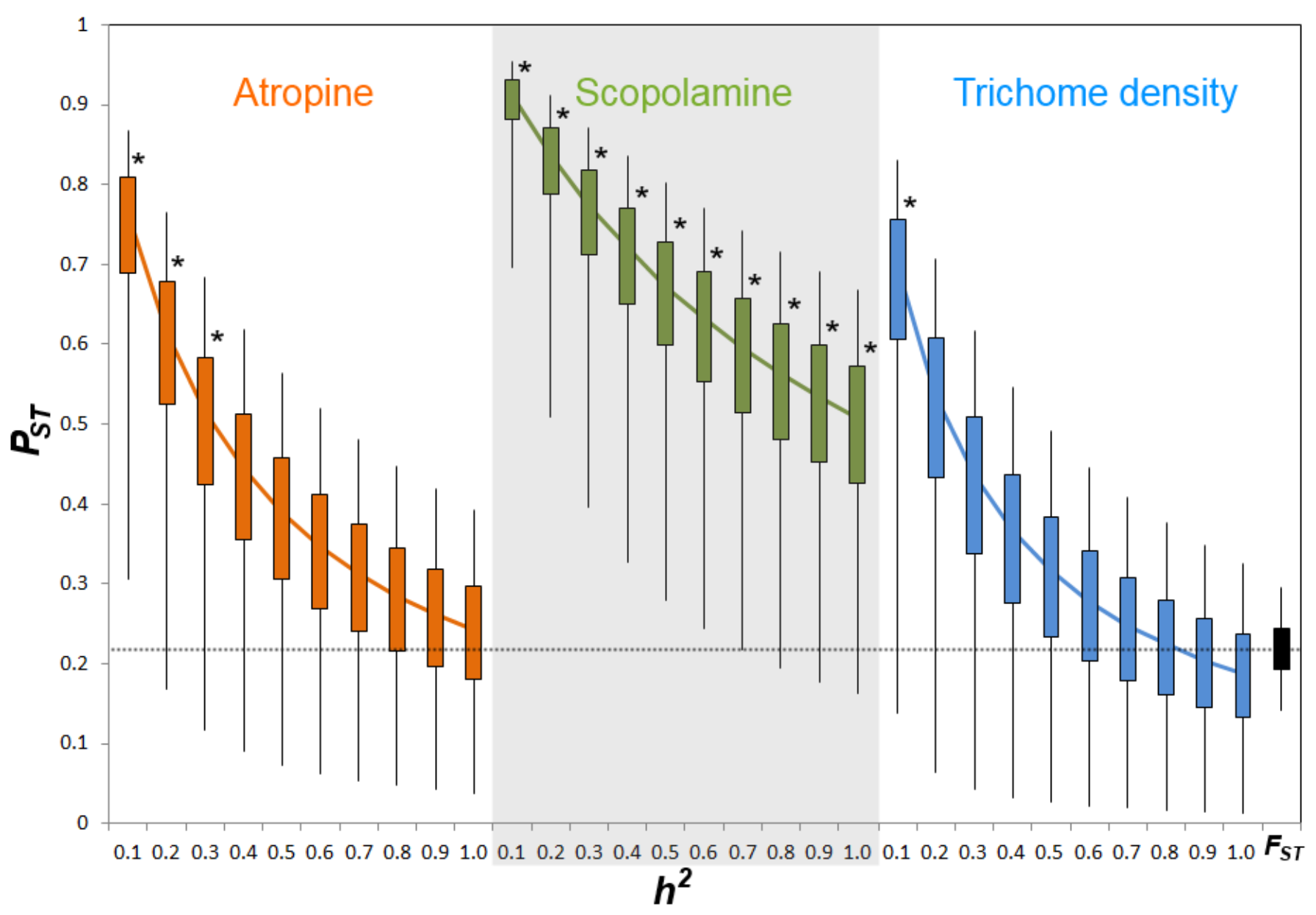




\section{Figure 4(on next page)}

\section{Figure 4}

Figure 4. Theoretical relationship between pair-wise $P_{S T}$ and pair-wise $F_{S T}$ across populations of a species. The solid diagonal line indicates a perfect and positive correlation between both indices $\left(r=1, P_{S T}=F_{S T}\right)$. Above the diagonal, blue points are pairs of populations where $P_{S T}>$ $F_{S T}$. Below the diagonal, orange points are pairs of populations where $P_{S T}<F_{S T}$. Dotted line indicates one possible scenario where both indices are uncorrelated. At moderate values of $F_{S T}$ stabilizing selection might be promoting low phenotypic differentiation between a given pair of populations (big orange point). 


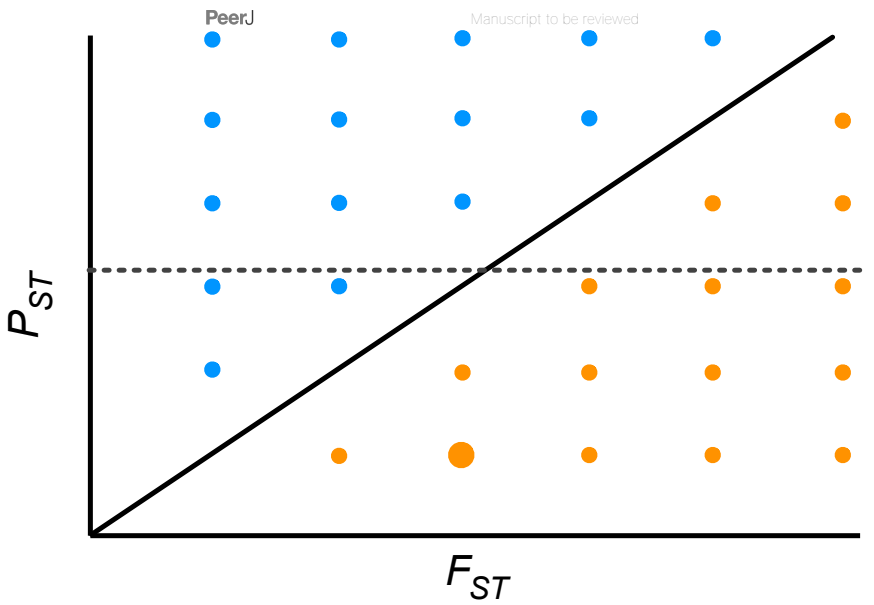

